\title{
A GREEN SYNTHESIS OF $\alpha, \beta$-UNSATURATED CARBONYL COMPOUNDS FROM GLYCERALDEHYDE ACETONIDE
}

Cláudia O. Veloso*, Cristiane A. Henriques e Ayres G. Dias

Instituto de Química, Universidade do Estado do Rio de Janeiro, Rua São Francisco Xavier, 524, 20559-900 Rio de Janeiro - RJ, Brasil Evanoel C. de Lima

Núcleo de Pesquisas de Produtos Naturais, Universidade Federal do Rio de Janeiro, 21941-590 Rio de Janeiro - RJ, Brasil

Bianca M. Souza e José Luiz F. Monteiro

Núcleo de Catálise, Universidade Federal do Rio de Janeiro, CP 68502, 21941-972 Rio de Janeiro - RJ, Brasil

Recebido em 18/6/10; aceito em 3/11/10; publicado na web em 18/2/11

\begin{abstract}
The catalytic behavior of Cs-exchanged and Cs-impregnated zeolites ( $\mathrm{X}$ and $\mathrm{Y}$ ) was studied using the Knoevenagel condensation between glyceraldehyde acetonide and ethyl acetoacetate in order to produce the corresponding $\alpha, \beta$-unsaturated carbonyl compound that is an important intermediate for fine chemicals. The influence of reaction temperature, type of zeolite, and basicity of the sites on the catalytic behavior of the samples was evaluated. All zeolites were active for the studied reaction. The formation of the main condensation product was favored at lower reaction temperatures. Products of further condensations were also observed especially for samples that were only dried before catalytic test.
\end{abstract}

Keywords: Knoevenagel condensation; glyceraldehyde acetonide; basic zeolites.

\section{INTRODUCTION}

The recent concern about the environment is inducing the chemical industry to develop environmentally benign products and processes that are based on the principles of the so-called Green Chemistry or Sustainable Chemistry. ${ }^{1,2}$ Solid catalysts are being used to replace liquid homogeneous catalysts so that less pollutant and more selective chemical processes could be developed. The use of heterogeneous catalysts decreases corrosion risk and the amount of toxic wastes, and allows an easy separation, recovery and reuse of the catalyst.

Enantiopure acceptors prepared from D-(+)-mannitol are among the most popular acceptors for conjugate additions studies and total enantioselective synthesis. ${ }^{3,4}$ 2,3-O-Isopropilydeneglyceraldehyde or glyceraldehyde acetonide is a chiron compound easily obtained in its $\mathrm{R}$ form from $\mathrm{D}-(+)-$ mannitol. This aldehyde is a compound largely used due to its enantiomers availability from natural resources, and its versatility related to the presence of the carbonyl group and the protected diol group. ${ }^{5-7} \alpha, \beta$-unsaturated carbonyl compounds obtained from glyceraldehyde acetonide are excellent Michael acceptors and one of the most used chirons in methodological studies and enantiomeric synthesis. ${ }^{8}$ Recently, ethyl (S)-(+)-3-(2,2-dimethyl1,3-dioxolan-4-yl)-trans-2-propenoate, an important building block obtained from glyceraldehyde acetonide, is commercially available, 5 g/US\$ 236.50. ${ }^{9}$ Usually, $\alpha, \beta$-unsaturated carbonyl compounds obtained from glyceraldehyde acetonide are obtained by the Wittig reaction that presents several disadvantages such as a large number of steps and the production of triphenylphosphine as by product. ${ }^{10}$

Considering the great applicability of these $\alpha, \beta$-unsaturated carbonyl compounds, the significantly high value of these compounds, and the low ecofriendly approach in use of Wittig reaction, the study of new routes to produce them is very relevant in the field of organic intermediates production. The aldol condensation of glyceraldehyde acetonide

*e-mail: co.veloso@hotmail.com with acetone was studied in liquid phase over basic solid catalysts, ${ }^{11} \mathrm{a}$ $\mathrm{Mg}, \mathrm{Al}$-mixed oxide and an X zeolite exchanged and impregnated with cesium. Both heterogeneous catalysts were active to the production of the $\alpha, \beta$-unsaturated carbonyl compound derived from glyceraldehyde acetonide and acetone. However, side reactions also occurred. Another alternative route to synthesize $\alpha, \beta$-unsaturated carbonyl compounds is the Knoevenagel condensation between glyceraldehyde acetonide and active methylene compounds such as ethyl acetoacetate (Figure 1). The Knoevenagel reaction is a nucleophilic addition of an active methylene compound to a carbonyl group followed by dehydration in the presence of a homogeneous or heterogeneous basic catalyst. ${ }^{12-15}$ This methodology is particularly used for the chain extension of aromatic aldehydes and widely employed for carbon-carbon bond formation in organic synthesis with numerous applications in the fine chemicals and bioactive compounds preparations..$^{16,17}$ Veloso et al. ${ }^{18}$ have studied the Knoevenagel condensation of glyceraldehyde acetonide and ethyl acetoacetate over $\mathrm{Mg}$,Al-mixed oxides with different $\mathrm{Al} /(\mathrm{Al}+\mathrm{Mg})$ molar ratio. All catalysts presented good glyceraldehyde acetonide conversion and were $100 \%$ selective to the condensation product.
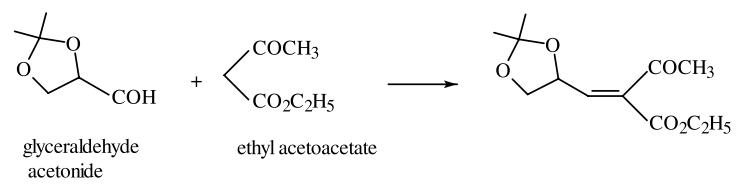

$+\mathrm{H}_{2} \mathrm{O}$

Figure 1. Knoevenagel condensation between glyceraldehyde acetonide and ethyl acetoacetate

Basic zeolites have emerged as interesting catalysts in several processes because of the important zeolite features, like, high specific surface area and a large range of acid-base properties. Different methods are used to tailor zeolite basicity. The decrease of the silica/alumina molar ratio (SAR), the exchange of the compensation cations by less electronegative ones, and the impregnation of basic 
compounds on the zeolite framework can increase the zeolite basicity. Cesium-exchanged $\mathrm{X}$ zeolites impregnated with cesium basic compounds have been successfully used as basic catalysts in several reactions ${ }^{19-21}$ including the synthesis of organic intermediates. ${ }^{22,23}$

In this work, the Knoevenagel condensation reaction between glyceraldehyde acetonide and ethyl acetoacetate over cesium exchanged and cesium impregnated zeolites (X and $\mathrm{Y}$ ) was studied aiming at evaluating the influence of reaction temperature, type of zeolite, and thermal treatment used before the reaction on the catalytic performance of the prepared zeolites.

\section{EXPERIMENTAL}

\section{Reagents}

(R)-Glyceraldehyde acetonide was prepared according to Mann et al..${ }^{24}$ Ethyl acetoacetate, ethyl malonate, ethyl cyanoacetate, and all reagents used in the preparation of the catalysts were technical grade.

\section{Catalyst preparation}

The parent materials used in this work were zeolites $\mathrm{X}$ (SAR = $2.3)$ and $Y(S A R=4.5)$ in the sodium form. The $X$ zeolite was supplied by IPT (Institute for Technological Research, São Paulo, Brazil), while Y zeolite was synthesized according to Silva. ${ }^{25}$ These zeolites were exchanged twice with a $\mathrm{CsCl}$ solution at $80^{\circ} \mathrm{C}$ for $1 \mathrm{~h}$, using a molar ratio of cesium in solution to total cations in the zeolite equal to 0.76 and 0.39 for zeolites $X$ and Y, respectively, in each step. After each ion-exchange step, the catalyst was filtered, washed with hot water and dried at $120^{\circ} \mathrm{C}$. For the impregnation with cesium species, the exchanged zeolites were suspended in a $2 \mathrm{~mol} \mathrm{~L}^{-1}$ cesium acetate solution ( $1 \mathrm{~g}$ of zeolite $/ 30 \mathrm{~mL}$ of solution) and then stirred for $5 \mathrm{~h}$ at room temperature. After impregnation, the suspension was filtered without any washing process and dried at $100{ }^{\circ} \mathrm{C}$. These samples were named as $\mathrm{CsX} / \mathrm{CsAcO}$ and $\mathrm{CsY} / \mathrm{CsAcO}$.

In order to decompose the impregnated cesium acetate, the samples were calcined at a rate of $5{ }^{\circ} \mathrm{C} \mathrm{min}{ }^{-1}$ under a dry air flow, the temperature being held at $250{ }^{\circ} \mathrm{C}$ for $30 \mathrm{~min}$ and at 400 or $500{ }^{\circ} \mathrm{C}$, for $\mathrm{X}$ and $\mathrm{Y}$ zeolites, respectively, during $5 \mathrm{~h}$. The samples were calcined under different temperatures due to the stability of the parent zeolites. The samples were identified as CsX/CS and CsY/CS.

\section{Catalyst characterization}

The chemical composition of the samples was determined by atomic absorption spectrometry using a Perkin-Elmer AAS 1100B spectrometer. The amount of cesium impregnated species was evaluated by thermogravimetric and thermodifferential analyses (TGA/ DTA) carried out in a Rigaku Thermobalance TAS 100 under flow of air at $10^{\circ} \mathrm{C} \min ^{-1}$ up to $700{ }^{\circ} \mathrm{C}$. The crystalline framework of the zeolite samples was checked by means of infrared spectroscopy. The spectra were recorded in a Perkin Elmer 2000 Fourier Transform Infrared Spectrophotometer with a resolution of $4 \mathrm{~cm}^{-1}$. The wafers were prepared using $300 \mathrm{mg}$ of $\mathrm{KBr}$ and $1 \mathrm{mg}$ of zeolite. Textural properties such as specific surface area (BET), microporous volume (t-plot), and mesoporous volume (BJH) were determined by $\mathrm{N}_{2}$ adsorption-desorption at $-196{ }^{\circ} \mathrm{C}$ in a Micromeritics ASAP 2020.

\section{Reaction procedure}

The condensation reaction of glyceraldehyde acetonide and active methylene compounds such as ethyl acetoacetate, ethyl malonate, ethyl cyanoacetate was carried out in liquid phase without solvent in a glass batch reactor magnetically stirred and heated by a thermostatic bath. The reaction system was kept under nitrogen atmosphere at atmospheric pressure. Immediately before the runs, samples CsX/ $\mathrm{CsAcO}$ and $\mathrm{CsY} / \mathrm{CsAcO}$ were calcined ex-situ at a rate of $5^{\circ} \mathrm{C} \mathrm{min}{ }^{-1}$ under a dry air flow, the temperature being held at $250{ }^{\circ} \mathrm{C}$ for $30 \mathrm{~min}$ and at 400 and $500{ }^{\circ} \mathrm{C}$, for $\mathrm{X}$ and $\mathrm{Y}$ zeolites, respectively, during $5 \mathrm{~h}$, while samples $\mathrm{CsX} / \mathrm{CS}$ and $\mathrm{CsY} / \mathrm{CS}$, which were calcined during the preparation step, were just dried at a rate of $5{ }^{\circ} \mathrm{C} \min ^{-1}$ under a dry nitrogen flow, the temperature being held at 120 and $250{ }^{\circ} \mathrm{C}$ for 30 min and at 400 and $500{ }^{\circ} \mathrm{C}$, for $\mathrm{X}$ and $\mathrm{Y}$ zeolites, respectively, for 2 h. After the thermal treatment, the catalyst was rapidly transferred to the reactor containing the mixture of glyceraldehyde acetonide and active methylene compounds. The experimental conditions used were the following: reaction temperature $=30,50$, and $70{ }^{\circ} \mathrm{C}$; reaction time $=4 \mathrm{~h}$; active methylene compounds/glyceraldehyde acetonide molar ratio $=5 ; 5 \mathrm{wt} \%$ of catalyst (referred to the total amount of reactants).

The reaction products were analyzed by gas chromatography using a Chrompack 9000 chromatograph with a $50 \mathrm{~m} \mathrm{CP-Sil} \mathrm{5CB}$ capillary column and a flame ionization detector. The identification of the products distribution was checked by means of a Hewllet Packard GC-HP 6890 gas chromatograph coupled to a Hewllet Packard HP 5973 mass detector.

\section{RESULTS AND DISCUSSION}

\section{Physico-chemical properties of the catalysts}

Table 1 shows the chemical composition of the zeolite samples. The exchange level for cesium was about $50 \%$ of the original sodium cations for both $\mathrm{X}$ and $\mathrm{Y}$ zeolites. The amount of impregnated cesium atoms per unit cell was similar for both samples, 29 and 24 cesium atoms / unit cell, as calculated from the TGA results.

Table 1. Chemical composition of the zeolites

\begin{tabular}{cc}
\hline Sample & Chemical formula \\
\hline $\mathrm{NaY}$ & $\mathrm{Na}_{59} \mathrm{Al}_{59} \mathrm{Si}_{133} \mathrm{O}_{384}$ \\
$\mathrm{CsY}$ & $\mathrm{Na}_{28} \mathrm{Cs}_{31} \mathrm{Al}_{59} \mathrm{Si}_{133} \mathrm{O}_{384}$ \\
$\mathrm{CsY} / \mathrm{CS}$ & $\mathrm{Na}_{28} \mathrm{Cs}_{31} \mathrm{Al}_{59} \mathrm{Si}_{133} \mathrm{O}_{384} \cdot 29 \mathrm{CS}^{\mathrm{a}}$ \\
$\mathrm{NaX}$ & $\mathrm{Na}_{90} \mathrm{Al}_{90} \mathrm{Si}_{102} \mathrm{O}_{384}$ \\
$\mathrm{CsX}$ & $\mathrm{Na}_{46} \mathrm{Cs}_{44} \mathrm{Al}_{90} \mathrm{Si}_{102} \mathrm{O}_{384}$ \\
CsX/CS & $\mathrm{Na}_{46} \mathrm{Cs}_{44} \mathrm{Al}_{90} \mathrm{Si}_{102} \mathrm{O}_{384} \cdot 24 \mathrm{CS}^{\mathrm{a}}$ \\
\hline a: cesium atoms impregnated per unit cell
\end{tabular}

The main textural properties of the zeolite samples are presented in Table 2. The values of the microporous volume of the parent zeolites are in agreement with those in the literature, showing that they are wellsynthesed microporous materials. The presence of cesium cations and the high content of impregnated cesium species affect the textural characteristics of the samples. The decrease in both microporous volume and specific surface area is due to a significant pore blocking caused by the exchanged cesium cations and impregnated cesium species. These results show that the textural properties of the parent zeolites were modified by the preparation methods. However, it is important to note that the low value of the microporous volume is not related to loss of crystallinity.

For both types of zeolites, the maintenance of their structures was verified by checking the infrared bands related to the vibrations of the zeolite crystalline framework in the region of $1300-300 \mathrm{~cm}^{-1}$. $\mathrm{X}$-ray analysis was not used to evaluate the cristallinity of the Cscontaining zeolites, because these materials always present a decrease in the intensity of the diffraction peaks comparing to Na-containing samples. This decrease is due to the distortion of the crystal lattice caused by the introduction of the large cesium cation in the zeolite lattice. ${ }^{26-28}$ Figure 2 shows the infrared spectra of $\mathrm{NaX}$ zeolite and 
Table 2. Textural characteristics of the samples

\begin{tabular}{cccc}
\hline Sample & $\mathrm{S}^{\mathrm{a}}\left(\mathrm{m}^{2} \mathrm{~g}^{-1}\right)$ & $\mathrm{V}_{\text {meso }}^{\mathrm{b}}\left(\mathrm{cm}^{3} \mathrm{~g}^{-1}\right)$ & $\mathrm{V}_{\text {micro }}{ }^{\mathrm{c}}\left(\mathrm{cm}^{3} \mathrm{~g}^{-1}\right)$ \\
\hline $\mathrm{NaY}$ & 759 & 0.06 & 0.34 \\
$\mathrm{CsY}$ & 515 & 0.07 & 0.25 \\
$\mathrm{CsY} / \mathrm{CS}$ & 82 & 0.03 & 0.04 \\
$\mathrm{NaX}$ & 701 & 0.02 & 0.32 \\
$\mathrm{CsX}$ & 464 & 0.01 & 0.22 \\
$\mathrm{CsX} / \mathrm{CS}$ & 174 & 0.01 & 0.08 \\
\hline
\end{tabular}

a: specific surface area (BET); ${ }^{\text {b: }}$ BJH method; ${ }^{\mathrm{c}}$ : $\mathrm{t}$ - plot method

of its cesium exchanged (CsX) and cesium impreganted (CsX/CS) forms; no significant changes were observed in the range 1300-450 $\mathrm{cm}^{-1}$ indicating that the ion exchange step and the impregnation of cesium species did not affect crystallinity. Similar results were observed for $\mathrm{CsY}$ and $\mathrm{CsY} / \mathrm{CS}$ zeolites.

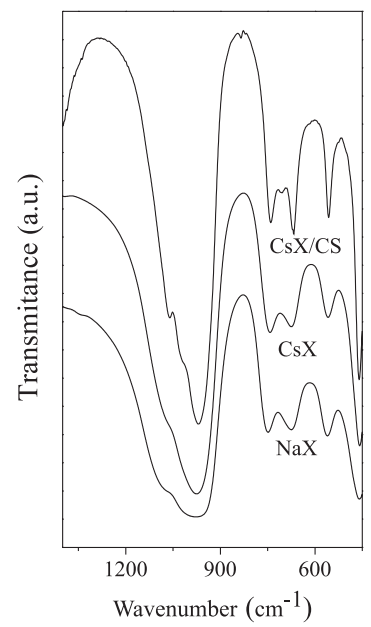

Figure 2. Infrared spectra of the zeolite samples

\section{Catalytic results}

The Knoevenagel condensation between glyceraldehyde acetonide and ethyl acetoacetate was carried out over the prepared catalysts. Figure 3 shows the reaction products obtained under the experimental conditions studied. These products were identified using their retention time in gas chromatography and their mass spectra.

The identified reaction pathways were the following: Knoevenagel condensation between glyceraldehyde acetonide and ethyl acetoacetate resulting in product (1); aldol condensation between product (1) and acetone, the latter being produced by ethyl acetoa-

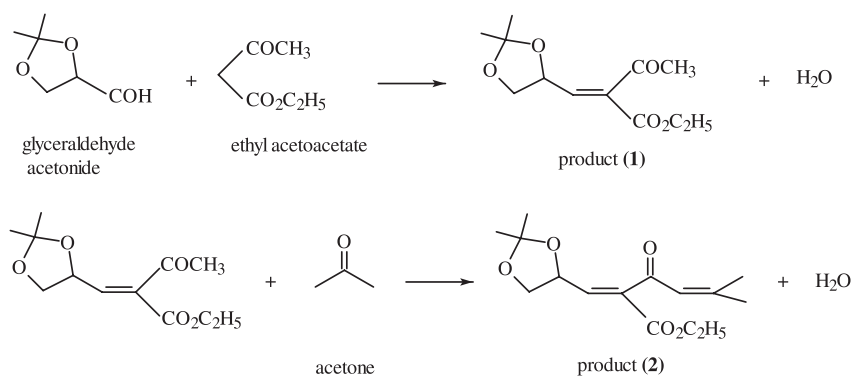

$\sum_{\mathrm{CO}_{2} \mathrm{C}_{2} \mathrm{H}_{5}}^{\mathrm{COCH}_{3}} \longrightarrow \overbrace{}^{\text {II }}+\mathrm{C}_{2} \mathrm{H}_{5} \mathrm{OH}+\mathrm{CO}_{2}$

Figure 3. Main reactions observed for the condensation between glyceraldehyde acetonide and ethyl acetoacetate cetate hydrolysis and decarboxylation, forming product (2).

The results of glyceraldehyde acetonide conversion and selectivity to products (1) and (2) are given in Tables 3 and 4. All tested samples were active for the Knoevenagel condensation. The product selectivity depends on the zeolite type and on the thermal treatment of the zeolite before the catalytic test.

Table 3. Catalytic results for the condensation of glyceraldehyde acetonide and ethyl acetoacetate over basic zeolites: $\mathrm{T}=70^{\circ} \mathrm{C}$; reaction time $=4 \mathrm{~h}$; ethyl acetoacetate/glyceraldehyde acetonide molar ratio $=5 ; 5 \mathrm{wt} \%$ of catalyst

\begin{tabular}{cccc}
\hline & & \multicolumn{2}{c}{ Selectivity $(\%)$} \\
Sample & Conversion $(\%)$ & $(\mathbf{1})$ & $(\mathbf{2})$ \\
\hline $\mathrm{CsX} / \mathrm{CS}$ & 71.0 & 18.7 & 81.3 \\
$\mathrm{CsX} / \mathrm{CsAcO}$ & 73.5 & 2.3 & 97.7 \\
$\mathrm{CsY} / \mathrm{CS}$ & 64.8 & 58.6 & 41.4 \\
$\mathrm{CsY} / \mathrm{CsAcO}$ & 79.0 & - & 100 \\
\hline
\end{tabular}

Table 4. Catalytic results for the condensation of glyceraldehyde acetonide and ethyl acetoacetate over CsY/CS zeolite: reaction time $=4 \mathrm{~h}$; ethyl acetoacetate/ glyceraldehyde acetonide molar ratio $=5 ; 5 \mathrm{wt} \%$ of catalyst

\begin{tabular}{ccccc}
\hline & & & \multicolumn{2}{c}{ Selectivity (\%) } \\
Sample & $\mathrm{T}\left({ }^{\circ} \mathrm{C}\right)$ & Conversion $(\%)$ & $(\mathbf{1})$ & $(\mathbf{2})$ \\
\hline $\mathrm{CsY} / \mathrm{CS}$ & 70 & 64.8 & 58.6 & 41.4 \\
$\mathrm{CsY} / \mathrm{CS}$ & 50 & 23.6 & 100 & - \\
$\mathrm{CsY} / \mathrm{CS}$ & 30 & 12.6 & 100 & - \\
$\mathrm{CsY} / \mathrm{CS}{ }^{1}$ & 30 & 44.9 & 100 & - \\
\hline
\end{tabular}

${ }^{1}$ : reaction time $=48 \mathrm{~h}$

A comparison of the catalytic behavior of samples CsX/CS and $\mathrm{CsY} / \mathrm{CS}$ at $70{ }^{\circ} \mathrm{C}$ shows that both catalysts present similar conversion of glyceraldehyde acetonide (Table 3 ). However, the selectivities to products (1) and (2) are very different. Under the experimental conditions studied, the formation of product (2) was favored over CsX/CS zeolite.

The first step in the aldol condensation of product (1) and acetone to form product (2) is the abstraction of an $\alpha$-proton from acetone on a basic site. The carbanion produced attacks the carbonyl group of product (1) forming product (2) after dehydration. The abstraction of an $\alpha$-proton from acetone and the attack of product (1) carbonyl group are steps that require basic sites stronger than those required for the same steps in the formation of product (1), the abstraction of a methylene proton of ethyl acetoacetate and the attack of the carbanion on the carbonyl group of glyceraldehyde acetonide. Thus, it can be suggested that the high selectivity to product (2) shown by CsX/CS zeolite, at $70{ }^{\circ} \mathrm{C}$, is associated to the presence of basic sites stronger than those present in CsY/CS.

As to the thermal treatment of the catalyst, when the decomposition of impregnated cesium acetate was done immediately before the reaction (samples $\mathrm{CsX} / \mathrm{CsAcO}$ and $\mathrm{CsY} / \mathrm{CsAcO}$ ) an increase on glyceraldehyde acetonide conversion was observed over $\mathrm{CsY} / \mathrm{CsAcO}$ sample and the aldol condensation of product (1) and acetone was favored. Thus, only product (2) was observed as reaction product. The results obtained over $\mathrm{CsX} / \mathrm{CsAcO}$ sample show that no significant change occurred on glyceraldehyde acetonide conversion, and that selectivity to product (2) increased. So, the condensation reaction between product (1) and acetone was favored over the samples in which the impregnated cesium species were decomposed immediately before the catalytic test and not exposed to ambient air. These results suggest that the exposure of the samples to ambient air after cesium acetate decomposition (samples CsX/CS and CsY/CS) produces sites with different basic properties. The high selectivity to product (2) could indicate the presence of stronger basic sites on $\mathrm{CsX} / \mathrm{CsAcO}$ and $\mathrm{CsY} / \mathrm{CsAcO}$ (calcined just before the catalytic test) than those present on CsX/CS and CsY/CS samples (dried before catalytic test). 
In order to better understand the catalytic behavior of CsY/CS and $\mathrm{CsY} / \mathrm{CsAcO}$ samples, different active methylene compounds were used as reactants. Ethyl malonate $\left(\mathrm{pK}_{\mathrm{a}}=13.3\right)$, ethyl acetoacetate $\left(\mathrm{pK}_{\mathrm{a}}=10.7\right)$ and ethyl cyanoacetate $\left(\mathrm{pK}_{\mathrm{a}}<9\right)$ are active methylene compounds with different $\mathrm{pK}_{\mathrm{a}}$ values. In this work, according to the catalytic performance of a basic catalyst as these active methylene compounds are used, a scale of basic strength of the catalytic sites will be established. The basic sites required to promoting the activation of ethyl cyanoacetate, ethyl acetoacetate and ethyl malonate will be classified as weak, intermediate and strong, respectively. The Knoevenagel condensation of the active methylene compounds with glyceraldehyde acetonide was used to measure the strength distribution of the basic sites of the $\mathrm{Y}$ zeolites studied. These results are shown in Figure 4. The higher glyceraldehyde acetonide conversions obtained with $\mathrm{CsY} / \mathrm{CsAcO}$ sample indicate that this sample has a slightly large amount of basic sites, most of the basic sites of both samples are weak with a significant amount of intermediate basic sites, and a small amount of strong basic sites. The similar profiles observed for both samples do not clearly explain the large amount of product (2) obtained over $\mathrm{CsY} / \mathrm{CsAcO}$ sample.

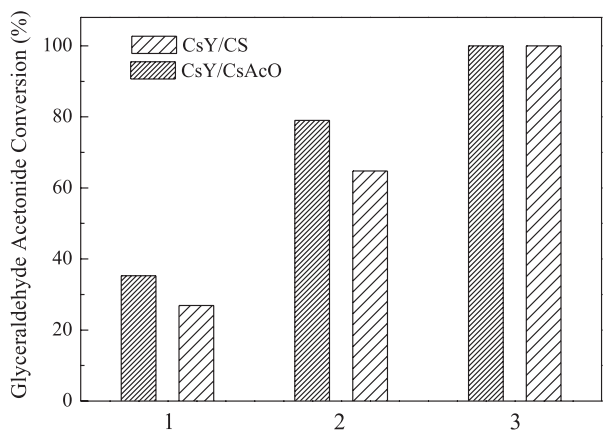

Figure 4. Catalytic results for the condensation of glyceraldehyde acetonide and ethyl malonate (1), ethyl acetoacetate (2), and ethyl cyanoacetate (3) over $C s Y / C S$ and $C s Y / C s A c O$ zeolites: reaction time $=4 h ; T=70^{\circ} \mathrm{C}$; active methylene compound/glyceraldehyde acetonide molar ratio $=5 ; 5 \mathrm{wt} \%$ of catalyst

The influence of the reaction temperature and time on conversion of glyceraldehyde acetonide and selectivity to products (1) and (2) was evaluated using sample CsY/CS. These results are shown in Table 4. As expected, the conversion of glyceraldehyde acetonide increased as the reaction temperature increased. At temperatures lower than $70{ }^{\circ} \mathrm{C}$, only product (1) was obtained.

The results shown in this work are related to the chemoselectivity of the catalysts. However, the maintenance of glyceraldehyde acetonide chirality is very important for the synthesis of pharmaceutical intermediates. The reaction temperature plays an important role on chirality. Lower reaction temperatures inhibit the loss of reagent chirality but also decrease conversion of the reagents. In this context, the catalytic behavior of $\mathrm{CsY} / \mathrm{CS}$ sample was evaluated at $30^{\circ} \mathrm{C}$ after 48 $\mathrm{h}$ of reaction time. This result is also shown in Table 4 . The increase of the reaction time causes an increase on glyceraldehyde acetonide conversion without any change on the selectivity of product (1). Although the conversion effect could not be neglected, these results suggest an important role of the reaction temperature on product (2) formation through the aldol condensation of product (1) and acetone.

\section{CONCLUSIONS}

The Cs-exchanged and Cs-impregnated zeolites (X and Y) were active for the Knoevenagel condensation between glyceraldehyde acetonide and ethyl acetoacetate. Under the reaction conditions used, for both catalysts, other reactions were observed such as aldol condensation between product (1), produced by the Knoevenagel condensation between glyceraldehyde acetonide and ethyl acetoacetate, and acetone, obtained by ethyl acetoacetate hydrolysis and decarboxylation. At 70 ${ }^{\circ} \mathrm{C}$, the activities of the zeolites were similar, but the selectivity to the products was influenced by the reaction temperature, the type of zeolite (X or Y), and the basicity of the sites, which in turn was influenced by the thermal treatment used before the catalytic test. For the CsY/CS sample, the decrease of the reaction temperature and the increase of reaction time favored the selective formation of product (1).

\section{ACKNOWLEDGMENTS}

C. A. Henriques would like to thank UERJ (Programa Prociência).

\section{REFERENCES}

1. Clark, J.; Green Chem. 1999, $1,1$.

2. Anastas, P.; Warner, J.; Green Chemistry: Theory and Pratice, Oxford University Press: New York, 1998.

3. Pisaneschi, F.; Piacenti, M.; Cordero, F.; Brandi, A.; Tetrahedron: Asymmetry 2006, 17, 292.

4. Kagawa, N.; Ihara, M.; Toyota, M.; Org. Lett. 2006, 8, 875.

5. Jurczak, J.; Pikul, S.; Baeur, T.; Tetrahedron 1986, 42, 447.

6. Mulzer, J.; Altenbach, H.-J.; Braun, M.; Krohn, K.; Reissig, H.-U.; Organic Synthesis Highlights, VCH Ed.: New York, 1990.

7. Lima, E.; Synlett 2009, 11, 1861.

8. Domingos, J.; Lima, E.; Dias, A.; Costa, P.; Tetrahedron: Asymmetry 2004, 15, 2313

9. http://www.sigmaaldrich.com/catalog/search/ProductDetail/ALDRICH/346810, accessed October 2009 and February 2011.

10. Trost, B.; Angew. Chem., Int. Ed. 1995, 34, 259.

11. Veloso, C.; Henriques, C.; Dias, A.; Monteiro, J. L.; Catal. Today 2005, 107-108, 294.

12. Corma, A.; Martin-Aranda, A.; Sanchez, F.; Stud. Surf. Sci. Catal. 1991, $59,503$.

13. Zhang, X.; Lai, E.; Martin-Aranda, R.; Yeung, K.; Appl. Catal., A 2004, $261,109$.

14. Angelescu, E.; Pavel, O.; Birjega, R.; Zavoianu, R.; Costentin, G.; Che, M.; Appl. Catal., A 2006, 308, 13.

15. Gawande, M.; Jayaram, R.; Catal. Commun. 2006, 7, 931.

16. Freeman, F.; Chem. Rev. 1980, 80, 329.

17. Tietze, L.; Chem. Rev. 1996, 96,115.

18. Veloso, C.; Pérez, C.; Souza, B.; Lima, E.; Dias, A.; Monteiro, J. L.; Henriques, C.; Microporous Mesoporous Mater. 2008, 107, 23.

19. Veloso, C.; Monteiro, J. L.; Souza-Aguiar, E.; Stud. Surf. Sci. Catal. 1994, $84 c, 1913$

20. Shabatai, J.; Lazar, R.; Biron, E.; J. Mol. Catal. 1984, 27, 35.

21. Ballini, R.; Bigi, F.; Gogni, E.; Maggi, R.; Sartori, G.; J. Catal. 2000, $191,348$.

22. Ebitani, K.; Motokura, K.; Mori, K.; Mizugaki, T.; Kaneda, K.; J. Org. Chem. 2006, 71, 5440.

23. Veloso, C.; Santos, E.; Pinto, A.; Monteiro, J. L.; Stud. Surf. Sci. Catal. 2001, 135, 237.

24. Mann, J.; Partlett, N.; Thomas, A.; J. Chem. Res. (S) 1987, 369.

25. Silva, D.; Tese de Mestrado, Universidade Federal do Rio de Janeiro, Brasil, 1993.

26. Kovacheva, P.; Arishtirova, K.; Davidova, N.; Appl. Catal., A 1999, 178, 111.

27. Hunger, M.; Schenk, U.; Weitkamp, J.; J. Mol. Catal. A: Chem. 1998, 134, 97.

28. Romero, M.; Ovejero, G.; Rodriguez, A.; Gomez, J.; Microporous Mesoporous Mater. 2005, 81, 313. 